Journal of Education and Vocational Research

Vol. 4, No. 10, pp. 293-299, Oct 2013 (ISSN 2221-2590)

\title{
Effect of Community Participation in Education on Quality of Education: Evidence from a Developing Context
}

\author{
Iqbal Ahmad, Hamdan Said \\ Universiti Teknologi Malaysia, Malaysia \\ shahnavi777@hotmail.com
}

\begin{abstract}
Education is an activity in collaboration. Without community participation, education cannot achieve its goals and without education society cannot think of development. A plethora of research exists on community participation in education and its outcomes. However, meager studies have been carried out to examine the relationship between community participation and quality of education. Although quality of education cannot be determined by one or two indicators. Research has already discovered many indicators of quality of education. But this study specifically investigated into three essential indicators which are contextually relevant to a developing country. The three main indicators investigated in relation with community participation were access, retention and attendance. The main aim of this study was to find out whether or not community participation in education reduces the issues of access, retention and attendance at secondary school level. To collect data, the study surveyed 200 (female) and 300 (males) total $\mathrm{N}=500$ government secondary schools teachers in Khyber Pakhtunkhwa province of Pakistan. Data were collected, collated and statistically computed using Pearson Correlation and ANOVA to determine a correlation between the independent variable (community participation in education) and the three indicators of quality of education such as access, retention and attendance as dependent variables. Results of the study indicated a significantly positive correlation between community participation and all the three indicators of quality of education. The study proposes community participation in education as the high positive predictor of access to education, retention and attendance.
\end{abstract}

Keywords: Community participation in education, quality of education, access, retention, attendance

\section{Introduction}

Schools are community in miniature. Education is not an activity in isolation. It is an activity in collaboration. Without community participation, education cannot achieve its goals and without education society cannot think of development (Dash, 2004). Through community involvement in the education process, quality of educational activities in schools can be improved and enhanced (Saeed, 2001). Studies show that participation of various stakeholders from government to educational professionals and local community members such as, parents, students, and other local community organizations exercises a deeper effect on the performance of educational institutions in terms of improved access, retention of students and classroom attendance (Stern, 2003). According to an educational report, parent and community are the key factors which determine school effectiveness. Effective schools have better access and increased enrollment of students. Parents and community can improve children's readiness for school and also ensure their balanced nutrition and health. This directly positively affects the quality of education (Education World, 1998). Research has underscored many benefits of community participation in education. For example, in the recent past, Rose (2003) found that community participation improves access to schooling. In this regard, he further explains that participatory initiatives in education in different under-developing countries such as Mali, Ghana, South Sudan, Ethiopia and Uganda have proved that access to schooling has greatly increased as a result of community participation in education. In Ethiopia alone, an overall school enrollment has increased up to 8.9 percent whereas, girls' enrollment has gone up to 13.8 percent. One important reason for increased enrollment in community schools is through awareness raising initiatives within the communities. Studies have further enumerated that retention and attendance in education can also be enhanced by proper monitoring and follow up on absence. For this purpose some efforts could be useful such as child-to-child strategies as well as home visits by the schoolteachers, head teachers, and other community member (Westheimer, 1998; Adam, 2005). Researchers have reported that participation of parents in educational 
endeavors contributes to improvement in the enrolment and retention of pupils, maintenance of school facilities, learning environment, and overall quality and long- term impact of education. Thus community participation in education greatly improves quality, relevancy, effectiveness and sustainability of all the educational initiatives that are undertaken to meet the needs of the communities. This can also be done through transferring the funds to school boards and engaging the school community based management (Uemura, 1999; Romi, 2000).

Research has indicated that community participation in education ensures maximization of limited resources for education, developing relevant curriculum and learning materials, identifying and addressing problems that hinder the development of education (Singleton, 2005). Participation of the community in educational outdoor activities such as visits and excursions of schools plays positive role in enhancing motivation and achievement rates of students (Smith, 2006). Research has found that community involvement in the policy formulation is very helpful in creating a sense of ownership in the community and also in developing a consensus among all the stakeholders, which in turn can lead to better satisfaction of the educational needs of the community. It also helps in successful implementation of the educational initiatives (Pannah, 2003). Participatory activities help achieve the goals of education where the government education initiatives had proved less sufficient in remote communities and marginalized groups (Anwar, 2001). In Gambia, low attendance of girls in schools has been effectively dealt with through community based social initiatives. For this purpose policy measures were adopted to counteract the bias against the disadvantaged sections of the community. In this regard, Non Government Organizations (NGOs) have especially played a beneficial role in bringing the educational opportunities to the poorest and marginalized communities especially for woman in collaboration with other community based organizations (Anees, 2000).

Ali (2005) has highlighted that through community participation in education many benefits can be achieved such as improved quality, easy access and sustainability. For this purpose, closely working with the local communities and assisting them in maximizing their available resources and the educational efforts are important to achieve these objectives. Condy (1998) has noted that the experience of participation is also helpful in creating awareness among the communities to collect and contribute resources in cash material or labour to school construction, giving teacher salaries and meeting other needs of the schools. Parents and other community members can contribute through fees and voluntary services. In another study, it was found that participation of the stakeholders in the educational management and implementation programmes helps bring long-term benefits to the people in strengthening of educational institutions' capacities. Thus the process of participation empowers the people and organizations equally and increases their capacities and abilities (Burde, 2004). Researchers have identified different ways of participation in the process of education such as, through forming parent teacher association which is basically a body consisting of parents, teachers or guardians who have children in the schools. Second, the school management committee, that aims at fostering effective community participation and mobilization for efficient education provision and delivery (Davies, 1996). This joint body represents the entire school community of a particular school. Third, the village education committee, which usually consists of the parents of the children and some other members of the community, has a stake in the process of education. Writers have concluded that schools, families and the communities can productively collaborate and work among themselves to achieve the goals of education (Coppola, Luczak, \& Stephenson, 2003).

Uemura (1999) has discussed in detail that community involvement in education can be facilitated for improving educational endeavors through various ways: (a) parenting (helping the families to establish home environments that support children's learning at schools). (b) communicating (designing effective forms of school-to-home and home-to-school communication that enable parents to learn about school programs and their children's progress in schools as well as teachers to learn about how children do at home). (c) volunteering (recruiting and organizing parent help and support for the management and administration of schools so that the resources could be utilized in the best possible manner). (d) Learning at home (providing information and ideas to families about how to help students at home with homework and other curriculum related activities, decisions and planning). (e) Decision-making (including families in school decisions, to have parent leaders and representatives in school meetings), and f) Collaborating (identifying and integrating resources as well as services from the community in order to strengthen school programs, family practices and students learning). Cairey and Ruge (1996) have further argued that the basic aim of involving 
communities, parents and families in education is to bring about improvement in the educational services and to ensure that children find better learning opportunities.

Research has found that twenty first century parents and communities are becoming more aware of the shared responsibility for the education of their children (Morgan, 2006). Studies have even termed community participation in education a predictor for better educational development of their children and improvement in the quality, access and sustainability of the educational initiatives (Johnson \& Goode, 1996; Katz, 2000). According to Shakeel (2004), this realization is also taking place in other of the world. For example, in Pakistan, government encourages parental and community participation in education, but the pace of participation is slow and the mechanisms for effective implementation are poor. Research has reported that parents, teachers, communities and other local organizations may join hands for improving the quality of education (Alfred \& Edwards, 2000). This study examined the effect of community participation on the three indicators of quality education. For this purpose the following research framework was designed. The below given research framework consists of three essential dimensions of community participation in education: volunteerism, collaboration and communication. The framework explains how these three dimensions of community participation affect education.

\section{Research Framework}

Figure 1: Research Framework

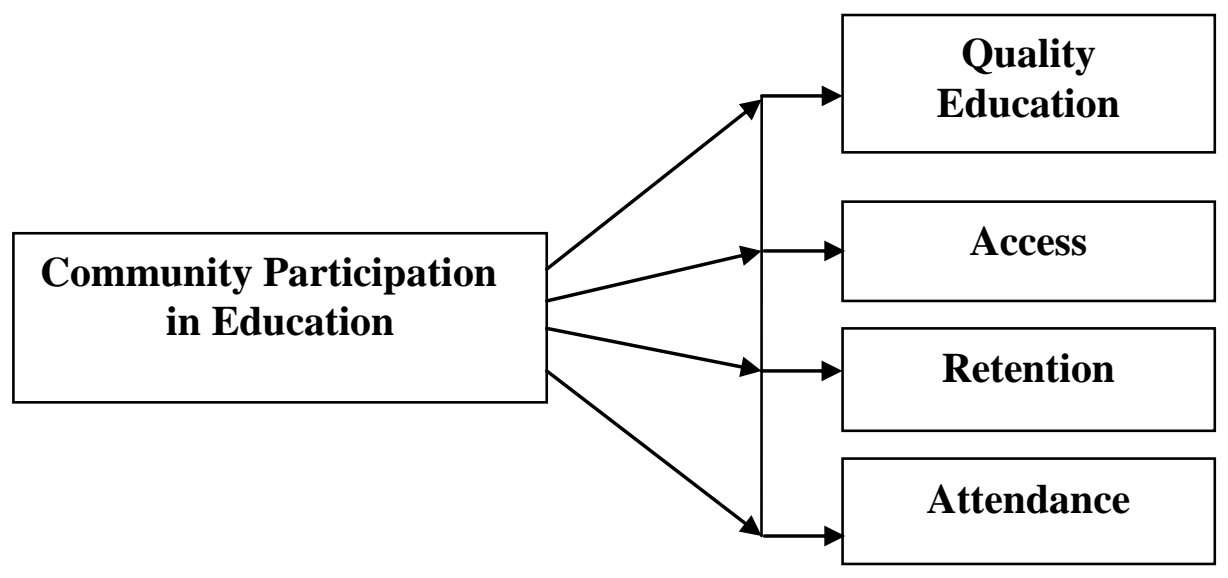

The above framework was specifically designed to test the hypotheses of this current study only. This framework has not been used in earlier studies. For this purpose, the following objectives were formulated to achieve the aim of this study.

Research objectives: The main objective of this research study was to investigate the effect of community participation in education on quality of education. More specifically the objectives of the study were:

- To investigate the effect of community participation in education on access.

- To investigate the effects of community participation in education on retention

- To investigate the effect of community participation in education on attendance

Research questions: The present research study attempted to answer the following research questions:

- Is there a relationship between community participation in education and quality education?

More specific sub-questions were:

- Is there a relationship between community participation in education and access?

- Is there a relationship between community participation in education and retention?

- Is there a relationship between community participation in education and attendance?

Hypotheses of the study: Based on the research objectives and questions the following hypotheses were formulated. 
- There is a positive relationship between community participation in education and quality education.

- There is a positive relationship between community participation in education and access.

- There is a positive relationship between community participation in education and retention.

- There is a positive relationship between community participation in education and attendance.

\section{Method and Procedures}

This research study was designed based on the following method and procedures.

Design: Using a correlation design, this study surveyed secondary teachers (200 female) and (300 males) total $\mathrm{N}=500$ from the target population of total 6000 government secondary schools teachers in Khyber Pakhtunkhwa province of Pakistan. Questionnaire was used for data collection from the respondents by using Five Point Likert Scale ranging from strongly disagree (1) to strongly agree (5). Statistical software SPSS version 18 was used to analyze the data.

Participants: Participants for this study were 500 (300 male) and (200 female) secondary school teachers in Malakand division of Khyber Pakhtunkhwa, Pakistan.

Sampling procedure: The participant teachers were randomly sampled from a target population of 6000 secondary school teachers from different schools where the concept of community participation in education has been integrated through forming Parent Teacher Associations (PTAs). As a result of the initiatives by the government after the passage of devolution plan in 2002, schools are working closely with communities through Parent Teacher Associations (PTAs). The main purpose of the parent teacher association is to strengthen relationship between schools and community.

\section{Analysis of data}

The purpose of this study was to examine relationship between community participation and quality education. Analysis of the data is presented in the below tables followed by findings and conclusions.

Correlation analysis: Correlation analysis was conducted to examine the relationship between independent variable (community participation in education) and the dependent variables (quality education and its three indicators).

Table 1: Correlation Analysis of community participation in education and the three indicators of quality education

\begin{tabular}{lllll}
\hline Variables & CPE & Access & Retention & Attendance \\
\hline Community participation in education (CPE) & 1 & & & \\
Access & $0.756^{*}$ & 1 & & \\
Retention & $0.76^{*}$ & $0.661^{*}$ & 1 & \\
Attendance & $0.64^{*}$ & $0.78^{*}$ & $0.75^{*}$ & 1 \\
\hline
\end{tabular}

*Correlation is significant at the 0.01 level (2-tailed).

Table 1 show that community participation in education is highly positively correlated with quality education and significant at $p$ value of 0.01 . Access, retention and attendance have also a highly positive relationship with education and Pearson correlation values and significant at $p$ value of 0.01 .

Regression analysis: Regression analysis was measured by testing the research hypotheses. The results for each variable are discussed as under.

$\mathrm{H}_{1}$ : There is a positive relationship between community participation in education and quality education. 
Table 2: Analysis of community participation in education and quality education

\begin{tabular}{|c|c|c|c|c|c|c|c|}
\hline Variables & & & R square & t-value & Coefficient & F-value & P value \\
\hline $\begin{array}{l}\text { Community } \\
\text { education }\end{array}$ & participation & in & 0.763 & 13.32 & 0.65 & 377.0 & 0.00 \\
\hline
\end{tabular}

Table 2 show the value of coefficient beta is calculated as 0.65 which shows a highly positive relationship between community participation in education and quality education. The value of R-square is calculated as 0. 763 showing $76.3 \%$ variation in the dependant variable (quality education is explained by independent variable (community participation in education). The model's goodness of fit is shown by F-value that is 377.0. Hence, $\mathrm{H}_{1}$ was accepted and supported that community participation in education has a significantly positive correlation with quality education.

$\mathrm{H}_{2}$ : There is a positive relationship between community participation in education and access

Table 3: Analysis of community participation in education and access

\begin{tabular}{lcccccc}
\hline Variables & R square & t-value & Coefficient & F-value & P value \\
\hline $\begin{array}{l}\text { Community } \\
\text { education }\end{array}$ & participation & in & & & & \\
\end{tabular}

Table 3 show the value of coefficient beta is measured as 0.78 which shows a significantly positive relationship between community participation in education and access. The value of R-square is calculated as 0.651 showing $65.1 \%$ variation in the dependant variable (access) is explained by independent variable (community participation in education). The model's goodness of fit is shown by F-value that is 268.1. Therefore $\mathrm{H}_{2}$ is accepted and supported that community participation in education has a significantly positive relationship with access.

$\mathrm{H}_{3}$ : There is a positive relationship between community participation in education and retention

Table 4: Analysis of community participation in education and retention

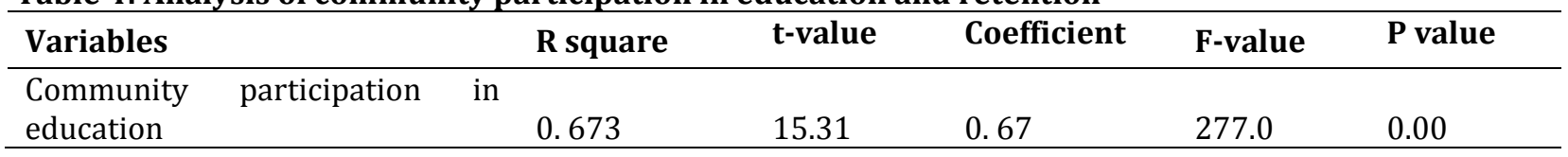

The value of co-efficient beta is calculated as 0.67 which shows a significantly positive relationship between community participation in education and quality education. The value of R-square is 0.673 showing $67.3 \%$ variation in the dependant variable (retention) is explained by independent variable (community participation in education). The model's goodness of fit is shown by F-value that is 277.0. Therefore, $\mathrm{H}_{3}$ is accepted and supported that community participation in education has a significantly positive correlation with retention.

$\mathrm{H}_{4}$ : There is a positive relationship between community participation in education and attendance

Table 5: Analysis of community participation in education and attendance

\begin{tabular}{lcccccc}
\hline Variables & & R square & t-value & Coefficient & F-value & P value \\
\hline $\begin{array}{l}\text { Community } \\
\text { education }\end{array}$ & participation & in & & & & \\
\hline
\end{tabular}

The value of co-efficient beta is calculated as 0.77 which shows a significantly positive relationship between community participation in education and quality education. The value of R-square is 0.663 showing $66.3 \%$ variation in the dependant variable (attendance) is explained by independent variable (community participation in education). The model's goodness of fit is shown by F-value that is 287.0. Therefore, $\mathrm{H}_{3}$ is accepted and supported that community participation in education has a significantly positive correlation with attendance. 
Findings and Discussion: The purpose of this study was to investigate the effect of community participation in education on quality education and its three indicators such as access, retention and attendance. The study found a significantly positive correlation between community in education and quality education. This finding also further confirms the previous literature as mentioned above that collaboration between schools and community has a healthy effect on quality education. This develops sense of ownership among the community and parents own the school. The study also found a significantly positive correlation between community participation in education and access to education. This finding also supports the previous literature that access is an important outcome of community participation in education. When community members volunteer their services to schools, this develops trust and confidence among community members which directly contributes to access to education. The study further discovered that a significantly positive correlation between community participation in education and retention. This finding is closely related to the earlier finding (Dash, 2004) that retention results out of community participation in education, because clear communication between school and community facilitates the process of education of the child. It helps schools to inform the community about the educational activities which increases the retention rate of students. Last but not least, the study found that community participation in education is significantly correlated with attendance.

\section{Conclusion}

This study concludes that community participation in education is positively correlated with quality education. On the basis of this finding this study argues that community participation is essential for the success of educational initiatives. This study further argues that positive interaction between schools and communities helps in achieving the goals of quality education, because this interaction creates wider opportunities of closer work and cooperation between parents and teachers which contributes towards enhancing access, decreased retention and increased attendance. The study further concludes that close collaboration between school and community is important for the educational development of the child as well as the promotion of quality educational initiatives. Finally on the basis of the above literature and the findings of this current study, it is argued that community participation in education contributes towards improvement in equitable access, retention, quality and performance of the schools. Hence, home, school and community are closely dependent on each other. Thus community involvement acts as the wool upon which depends the very existence of the fabric of the society.

Future research: This study was conducted based on cross-sectional design for which data were collected just once during the study from a specific geographical area with a small sample base. Hence, it cannot be generalized to other places. It is recommended that future research should test the same design with increased sample base in other geographical areas. This will ensure more reliability and generalizability of the study results.

\section{References}

Adam, F. (2005). Community participation in school development: Understanding participation in basic school's performance in the Nunumba district of Ghana. Retrieved on October 28, 2012from http://www.bora.uib.no/bitstream/1956/1145/1/ADAM\%20THESISpdf

Alfred, P. \& Edwards, R. (2000). A typology of parental involvement in education centering on child and young people: Negotiating familiarization, institutionalization and individualization. British Journal of Sociology of Education, 21(3), 435-455

Ali, A. (2005). Suffocating children in the name of education. The Dawn, p. 25.

Anees, R. (2000). PTA: A general venture. The Dawn, p. 21.

Anwar, M. (2001). Rising through community participation. The Dawn, p. 24.

Burde, D. (2004). Weak state, strong community: Promoting community participation in post conflict countries. Retrieved on October 27, 2012 from http://www.columbia.edu.cice/Archives/6.2/62 burde.pdf

Condy, A. (1998). Improving the quality of teaching and learning through community participation: Achievements, initiations and risks. Early lessons from the schooling improvement fund in Ghana. Retrieved on May 5, 2012 from http://www.dfid.gov.uk-pubs/files/sbdwp2pdf 
Coppola, G.M., Luczak, C. \& Stephenson, M. (2003). Community participation in Decision-making process: World learning experience in Guatemala and Benin. Retrieved on May 17, 2012 from http://www.gwv.edu-oid/events/world-learning-participatory.doc

Cairey, T. \& Ruge, J. (1996). Bridging home and school literacy: In search of more effective partnerships. Forum of education, 51(1), 103.

Dash, B. N. (2004). Education and society. New Delhi: Dominant.

Davies, D. (1996). Crossing boundaries: community-school-family partnerships. Forum of education, 51(1), 25-38.

Education World. (1998). School family partnership: Enjoying the benefits, overcoming the barriers. Retrieved on June 10, 2012 from http://www.edcuactionworld.com/acurr/strategy/strategy005.shtml.

Johnson, V. R. \& Goode, D. A. (1996). The community portrait: Promoting positive images through schools, parents and community collaboration. Forum of education, 51(1), 23-33.

Katz, Y. J. (2000). The parent-school partnership: shared responsibility for the education of the children. Curriculum and teaching, 15(2), 96-102.

Morgan, S. J. (2006). What community participation in schooling means: Insights from southern Ethiopia. Retrieved on May 22, 2012 from http://www.hepg.org/dpcument/61

Pannah, K. (2003). The parent-teacher relationship. The Daily Dawn, p.21.

Romi, S. (2000). Educational interventions in family school partnership: Implications for the curriculum. Curriculum and teaching, 5(2), 61-86.

Rose, P. (2003). Communities, gender and education: Evidences from Sub-Saharan Africa. A background report for UNESCO global monitoring. Retrieved on May 10, 2012 frohttp://www.portal.UNESCO.org/education/eu/file_downlaod,php157aa4c/

Saeed, S. (2001). The math of effective education. The Dawn, p.24.

Shakeel, A. (2004). School organization and administration. Golden Publications: Hyderabad

Singleton, A. C. (2005). Think globally, act locally: An analysis of community participation discourse in education for all national action plans. Retrieved on June 23, 2012 from http://www.stanford.edu/dpt/SUSE/ICE/monogarphs/corrine-monograph.pdf

Smith, M. K. (2006). Community participation. Retrieved on May 10, 2012 fromhttp://www.infed.org/community/b_compar.htm

Stern, J. (2003). Involving parents. London: Continuum.

Uemura, M. (1999). Community participation in education: What do we know? Retrieved on May 12, 2012, from http://www.worldbank.org/education/est/resources/topic\%papers/partnership.doc

Westheimer, J. (1998). Conceptualizing community. Journal of research on education, 8(1), 22-37. 